Article

\title{
Plasmonic Detection of Glucose in Serum Based on Biocatalytic Shape-Altering of Gold Nanostars
}

\author{
Masauso Moses Phiri *D, Danielle Wingrove Mulder and Barend Christiaan Vorster *(D) \\ Centre for Human Metabolomics, North-West University, Potchefstroom 2520, South Africa \\ * Correspondence: missiphiri@gmail.com (M.M.P.); chris.vorster@nwu.ac.za (B.C.V.)
}

Received: 3 May 2019; Accepted: 24 June 2019; Published: 29 June 2019

check for updates

\begin{abstract}
Nanoparticles have been used as signal transducers for optical readouts in biosensors. Optical approaches are cost-effective with easy readout formats for clinical diagnosis. We present a glucose biosensor based on the biocatalytic shape-altering of gold nanostars via silver deposition. Improved sensitivity was observed due to the nanostars clustering after being functionalised with glucose oxidase (GOx). The biosensor quantified glucose in the serum samples with a 1:1000 dilution factor, and colorimetrically distinguished between the concentrations. The assay demonstrated good specificity and sensitivity. The fabricated glucose biosensor is a rapid kinetic assay using a basic entry level laboratory spectrophotometric microplate reader. Such a biosensor could be very useful in resource-constrained regions without state-of-the-art laboratory equipment. Furthermore, naked eye detection of glucose makes this a suitable biosensor for technology transfer to other point-of-care devices.
\end{abstract}

Keywords: glucose biosensor; gold nanostars; colorimetric detection; glucose oxidase; localized surface plasmon resonance; biocatalytic shape-altering

\section{Introduction}

Great interest was sparked in the further development of improved enzyme-based biosensors for glucose monitoring [1] after Clark and Lyons introduced their glucose monitor using glucose oxidase (GOx) and an oxygen electrode [2]. The measurement of glucose is of major importance as the incidence of diabetes continues to increase due to improved global living standards [3]. Many methods have since been designed for glucose detection, including electrochemistry $[1,4,5]$, fluorescence $[6,7]$, surface-enhanced Raman scattering (SERS) [8,9], and surface plasmon resonance [10-13].

Electrochemical glucose biosensors are the most widely used, clinically [8]. This approach, however, suffers from a number of disadvantages such as complexity of electrode preparation, lack of stability in signal acquisition, inactivation of electrodes by the generated $\mathrm{H}_{2} \mathrm{O}_{2}$, relatively high cost, and reproducibility concerns $[4,8,11,14,15]$. Other detection strategies such as, SERS, have also been explored owing to its high sensitivity. The method has the ability to provide clear fingerprint information to identify the structures of the molecules [8,9,16-18]. The disadvantage of using this method for glucose measurement is that glucose has an inherent weak Raman activity making it difficult to trace it directly by Raman spectroscopy. Despite efforts for SERS enhancements, the weak surface adsorption ability of glucose produces relatively low SERS signal [8].

Optical detection approaches have the advantage of being cost-effective with an easy readout format $[10,19]$. A number of optical approaches for glucose sensing based on nanoparticle plasmon resonance have been reported in the past decade $[10,20]$. These glucose sensors are either enzyme- or non-enzyme-based assays [20-22]. Using enzymes has the advantage of increasing specificity of the assays [11]. GOx, isolated and produced from the fungus Aspergillus niger, is the most popularly used enzyme for glucose monitoring due to its very high substrate specificity [11]. It oxidizes glucose in 
the presence of molecular oxygen producing hydrogen peroxide $\left(\mathrm{H}_{2} \mathrm{O}_{2}\right)$, which is used to determine glucose concentration $[1,11,20]$.

Four main strategies have been applied in optical signal generation using nanoparticles. These include, (i) nanoparticle aggregation; (ii) surface etching; (iii) fluorescence quenching; and (iv) nanocrystal growth [10,23-26]. Nanoparticle aggregation is the most commonly employed strategy for sensing. The disadvantage with this method however, is that it lacks specificity in signal generation, as many other factors in solution may cause particle aggregation [10-12]. Biocatalytic growth of nanoparticles for signal amplification has been applied for the development of many assays [23,26-29]. This mechanism has allowed the tuning of the plasmonic nanoparticle shape and size resulting in different optical properties [30]. Nanostructure shape-altering mechanism of detection is one of the strategies for enhancing the sensitivity of plasmonic nanosensors. As one of the anisotropic nanocrystals, gold nanostars (AuNSs), exhibit higher refractive index sensitivity compared to spherical nanoparticles [27]. Localised surface plasmon resonance (LSPR) sensing based on shape alterations induced by an external stimulus is highly sensitive to changes in the conditions within the colloidal or detection solution [31]. Particle size growth is more sensitive with small sized nanoparticles, as they have higher absorption rates compared to larger particles like AuNSs [27].

Most nanoparticle-based glucose biosensors developed were conducted in either buffer systems, urine, or saliva $[4,10,27,32-35]$. Yet, venous plasma or serum are the recommended body fluids for clinical glucose diagnosis [36-39]. Some methods have however reported using biological samples $[40,41]$. The complexity of a biological matrix substantially increases the probability of undesired interfering and side reactions. Therefore, the use of buffered systems is likely to make false assumptions about the usability of nanomaterials in clinical diagnostics [12,41-43]. Plasma or serum has many proteins and lipoproteins that form a corona around the nanoparticle and changes its physiochemical properties based on the biomaterials coated around it [40]. This corona affects the effective diameter of the nanoparticles, and increases the chances of aggregation. The biomolecular corona effectively changes the synthetic identity of the nanoparticles to biological identity based on the molecules attached. Additionally, Au and Ag disintegrate in serum, making the detection in biological samples difficult [34,41-52]. There is thus, a need to develop and optimise an optical biosensor that is stable, sensitive, and robust enough for detection of clinical samples.

In this work, a sensitive, specific, and rapid optical glucose sensor based on biocatalytic shape-altering of gold nanostars AuNSs is presented. The biosensor was fabricated by optimally functionalising seedless AuNSs with GOx for enhanced stability and functionality. The functionalised AuNSs were tested for stability in various fluids and thereafter optimised for glucose sensing in spiked serum samples. Lastly, a number of analytical parameters such as specificity, kinetics, and recovery of the glucose assay were investigated.

\section{Materials and Methods}

\subsection{Materials}

Hydrochloroauric acid $\left(\mathrm{HAuCl}_{4}\right)$, glucose oxidase (GOx), trisodium citrate, silver nitrate $\left(\mathrm{AgNO}_{3}\right)$, ascorbic acid, sodium chloride $(\mathrm{NaCl})$, polyvinylpyrrolidone (PVP) (molecular weight 10,000), hydrochloric acid ( $\mathrm{HCl})$, glucose, 2-( $\mathrm{N}$-morpholino)ethanesulfonic acid (MES) at pH 6, N-(3Dimethylaminopropyl)- $N$ '-ethylcarbodiimide hydrochloride (EDC), sulfo- $N$-Hydroxysuccinimide (sulfo-NHS), glucose, cysteine (Cys), and phosphate buffered saline (PBS) at pH 7.4 were all purchased from Sigma-Aldrich, South Africa. Ham's F-12K (Kaighn's) cell culture medium was used and supplemented with $10 \%$ foetal bovine serum (FBS), which were purchased from ThermoFisher Scientific. Medidrug Basis-line S human blank serum was purchased from Industrial Analytical, South Africa. All glassware was stripped with aqua regia prior to use for synthesis. Ultrapure water $\left(\mathrm{ddH}_{2} \mathrm{O}\right)$ was pre-prepared with a Milli-Q ultra-pure system $(18.2 \mathrm{M} \Omega / \mathrm{cm})$. 


\subsection{Preparation of AuNSs-Cys-GOx Bioconjugates}

Synthesis of the PVP-stabilised seedless AuNSs and subsequent GOx bioconjugation were done using recently published methods by Phiri et al. [53,54]. Briefly, $10 \mathrm{~mL}$ of $\mathrm{ddH}_{2} \mathrm{O}$ was acidified with $10 \mu \mathrm{L}$ of $1 \mathrm{M} \mathrm{HCl}$ followed by the addition of $50 \mu \mathrm{L}$ of $100 \mathrm{mM}$ ascorbic acid under mild stirring. Shortly after the addition of $50 \mu \mathrm{L}$ of $50 \mathrm{mM} \mathrm{HAuCl}_{4}$ to the mixture, $50 \mu \mathrm{L}$ of $10 \mathrm{mM} \mathrm{AgNO}_{3}$ was rapidly added to the solution which resulted in a deep blue colour change within a few seconds. Finally, $500 \mu \mathrm{L}$ of $2.5 \mathrm{mM}$ PVP was added to the mixture. Immobilisation of the enzyme onto the gold nanostars was done by adding $100 \mu \mathrm{L}$ of $0.02 \mathrm{mM}$ Cys to $2 \mathrm{~mL}$ of PVP-stabilised AuNSs after their clean-up, and left to incubate on a rotator for $3 \mathrm{~h}$. The chemical modification of the enzyme was prepared by adding $250 \mathrm{mM}$ of freshly prepared EDC/sulfo-NHS to $1 \mathrm{~mL}$ of GOx $(5 \mathrm{mg} / \mathrm{mL})$ in MES buffer $(10 \mathrm{mM}$, $\mathrm{pH} 6$ ) and allowed to react for $2 \mathrm{~h}$. Finally, the conjugation of the AuNSs-Cys-GOx bioconjugates was accomplished by pipetting $500 \mu \mathrm{L}$ of EDC/sulfo-NHS-modified enzymes and adding it to $2 \mathrm{~mL}$ of AuNSs-Cys, and incubating it overnight in the fridge. The mixture was thereafter centrifuged at $3000 \times g$ for $30 \mathrm{~min}$ to remove any unbound enzymes. The AuNSs-Cys-GOx bioconjugates were resuspended in MES buffer and stored at $4{ }^{\circ} \mathrm{C}$ until usage.

\subsection{Characterizations and Instrumentations}

UV-vis spectroscopy analyses were carried out by spectral scanning (400-990 nm) on an HT Synergy (BioTEK, VT, USA) microplate reader. The transmission electron microscopy (TEM) analyses were performed on a Tecnai F20 high-resolution transmission electron microscope (HR-TEM) at an accelerating voltage of $200 \mathrm{kV}$. Samples for TEM were prepared by applying $20 \mu \mathrm{L}$ of nanoparticle suspension onto carbon 200 mesh copper grids (Agar Scientific, Johannesburg, South Africa), followed by drying overnight prior to imaging. ImageJ software was used to determine the particles sizes from different grids. Proton nuclear magnetic resonance $\left({ }^{1} \mathrm{H}-\mathrm{NMR}\right)$ analyses of samples in various fabrication stages were done according to the method by Venter et al. [55]. Six hundred microliters of samples were measured at $500 \mathrm{MHz}$ on a Bruker Avance III HD NMR spectrometer equipped with a triple-resonance inverse (TXI) ${ }^{1} \mathrm{H}\left[{ }^{15} \mathrm{~N},{ }^{13} \mathrm{C}\right]$ probe head and $\mathrm{x}, \mathrm{y}, \mathrm{z}$ gradient coils. ${ }^{1} \mathrm{H}$ spectra were acquired as 128 transients in $32 \mathrm{~K}$ data points with a spectral width of $12,002 \mathrm{~Hz}$. Fourier transformation and phase and base line correction were done automatically. Software used for NMR processing was Bruker Topspin (V3.5). Bruker AMIX (V3.9.14) was used for metabolite identification [56].

\subsection{Stability of AuNSs-Cys-GOx Bioconjugates}

The stability of the AuNSs-Cys-GOx bioconjugates was tested in the MES buffer, blank serum, unsupplemented- and supplemented cell culture solutions. The GOx-modified gold nanostars were centrifuged and resuspended in $200 \mu \mathrm{L}$ of the above-mentioned fluids. UV-vis spectroscopy was used to investigate the stability of the bioconjugates and TEM analyses were done to observe the morphology and dispersity of the AuNSs in these fluids.

\subsection{Enzyme Activity Assays}

The optimised assay parameters reported in the recent study [54] were used to compare the signal generation for the determination of glucose in serum and MES buffer using AuNSs-Cys-GOx bioconjugates. The detection of glucose was assessed spectrophotometrically based on shifts in the LSPR peaks, and optically by colour changes in the solutions. Kinetic reads were done at $550 \mathrm{~nm}$ to determine the rate of signal generation after incubation. A number of analytical parameters were evaluated to assess the developed biosensor. Using spiked blank serum with varying concentrations of glucose, the specificity and calibration model were determined. The specificity was determined by spiking the serum with other glucose analogues such as fructose, galactose, and sucrose and their signal responses were compared under optimal conditions. Additionally, the sensing performance of 
the biosensor was assessed with serum lipids and cysteine instead of glucose. All experiments were carried out in triplicates.

\section{Results and Discussion}

\subsection{Characterisation of GOx-Modified AuNSs}

Figure 1A shows that UV-vis spectra of the GOx-modified AuNSs had their LSPR peak red-shift of $21.6 \pm 3.2 \mathrm{~nm}$ from the PVP-stabilised AuNSs. The redshift for the GOx-modified AuNSs bioconjugates from the PVP-stabilised ones resulted in changes in optical properties of the AuNSs as a result of the surface functionalisation with GOx. HR-TEM images in Figure 1B shows the morphologies of the PVP-stabilised AuNSs and the enzyme-modified AuNSs. The enzyme layer attached on the peripheral surface of the AuNSs could not be imaged due to low electron resistance of protein molecules in HR-TEM examination [57]. Thus, the HR-TEM was useful for imaging the structural integrity of AuNSs after enzyme attachment. Figure $1 \mathrm{C}$ shows the ${ }^{1} \mathrm{H}-\mathrm{NMR}$ spectra with discernible shifts and splitting on the modified molecules. The cysteine-modified AuNSs showed that these peaks were drawn together at $3.75 \mathrm{ppm}$, indicating a shift most likely due to the specific interaction of gold with the sulphur, as observed in other studies [58-60]. Spectrum (II) showed the bioconjugation of cysteine-modified AuNSs with GOx (using EDC/sulfo-NHS chemistry). The peaks slightly shifted for the ester-activated enzyme covalently coupled to AuNSs-Cys, thereby indicating a successful AuNSs-Cys-GOx conjugation.

\subsection{Stability and Characterisation of AuNSs-Cys-GOx Bioconjugates in Various Media}

Figure 2A shows the stability of the GOx-modified AuNSs in different media based on change in optical densities over time. The maximum optical density of the bioconjugates in MES buffer and unsupplemented cell culture medium was observed to decline with time due to possible aggregation. However, when incubated in serum the maximum optical density increased in the period between $0-2 \mathrm{~h}$ and slightly declined thereafter. The increase in absorption is probably due to the complexation of unspecified serum proteins [43]. The UV-vis spectra of the bioconjugates in serum displayed better stability and only seconded by those incubated in supplemented cell culture medium. The AuNSs in the supplemented cell culture medium showed a steady decline in the UV-vis absorption in the period between 0 to $6 \mathrm{~h}$ before stabilising over the remaining hours. This is probably due to the FBS with proteins likely bind to nanoparticles resulting in relative better stability in the media $[42,61]$. Figure 2B shows the morphologies of the AuNSs-Cys-GOx bioconjugates in the different matrices. The agglomeration of the AuNSs in serum (II) is noteworthy. Agglomeration was observed for these AuNSs compared to those in other matrices. A similar observation was made for AuNSs incubated in FBS-supplemented cell culture medium (IV). The particle agglomeration observed in these two fluids could be attributed to the changes in surface properties brought about by the biomolecules and the ionic strength in the serum that forms a corona around the nanoparticles $[41,43,44]$. 

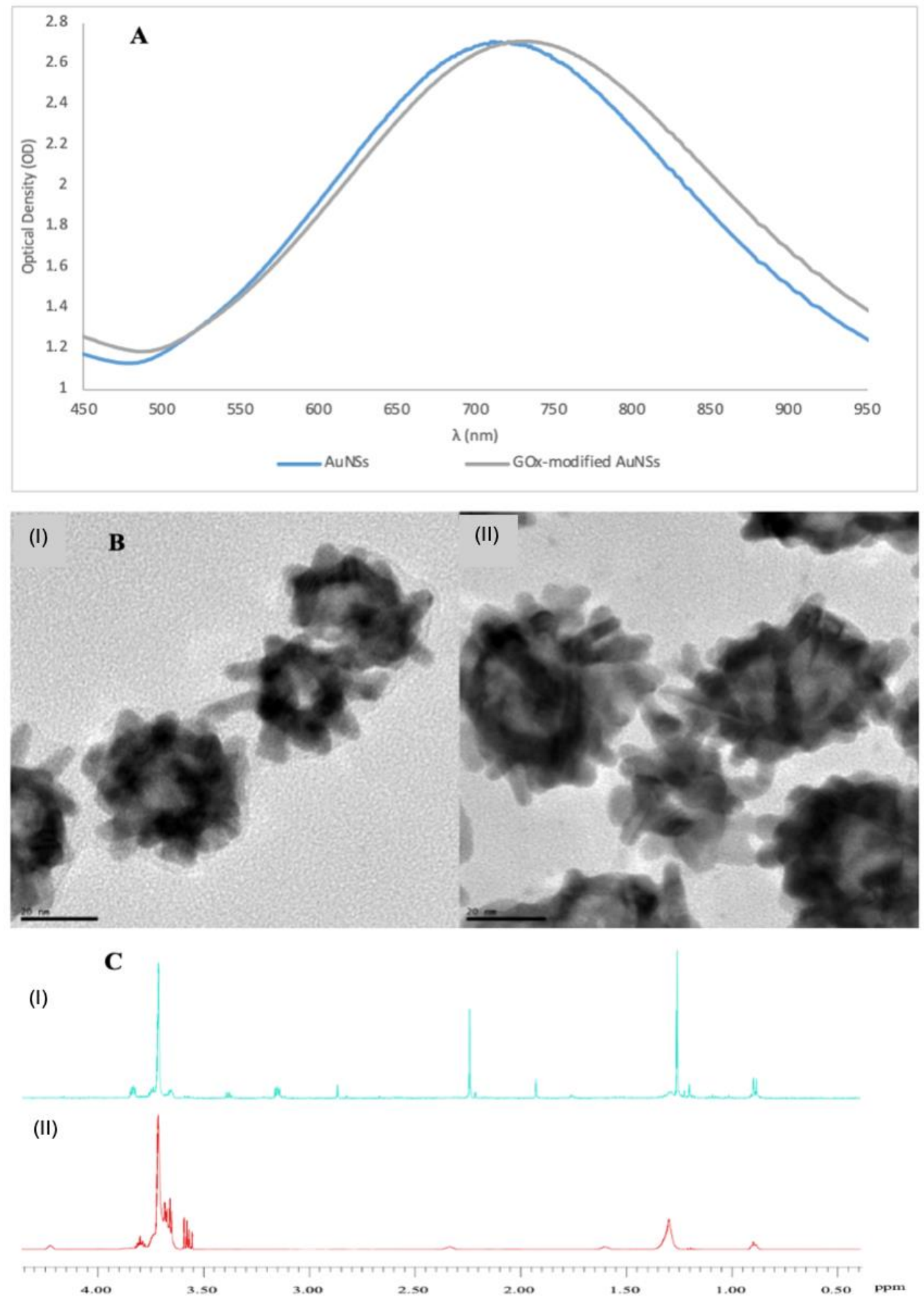

Figure 1. (A) Normalised UV-vis spectra showing a red-shift for the AuNSs modified with $0.042 \mathrm{mmol} / \mathrm{L}$ of glucose oxidase (GOx). (B) High resolution transmission electron microscope (HR-TEM) images of (I) polyvinylpyrrolidone (PVP)-stabilised AuNSs, and (II) GOx-modified AuNSs. (C) ${ }^{1} \mathrm{H}-\mathrm{NMR}$ spectra of (I) cysteine-modified AuNSs, and GOx-modified AuNSs using cysteine and $\mathrm{N}$-(3-Dimethylaminopropyl)- $\mathrm{N}^{\prime}$-ethylcarbodiimide hydrochloride (EDC)/sulfo-NHS for bioconjugation. (The images were adapted and used with permission from Phiri et al. [53]). 

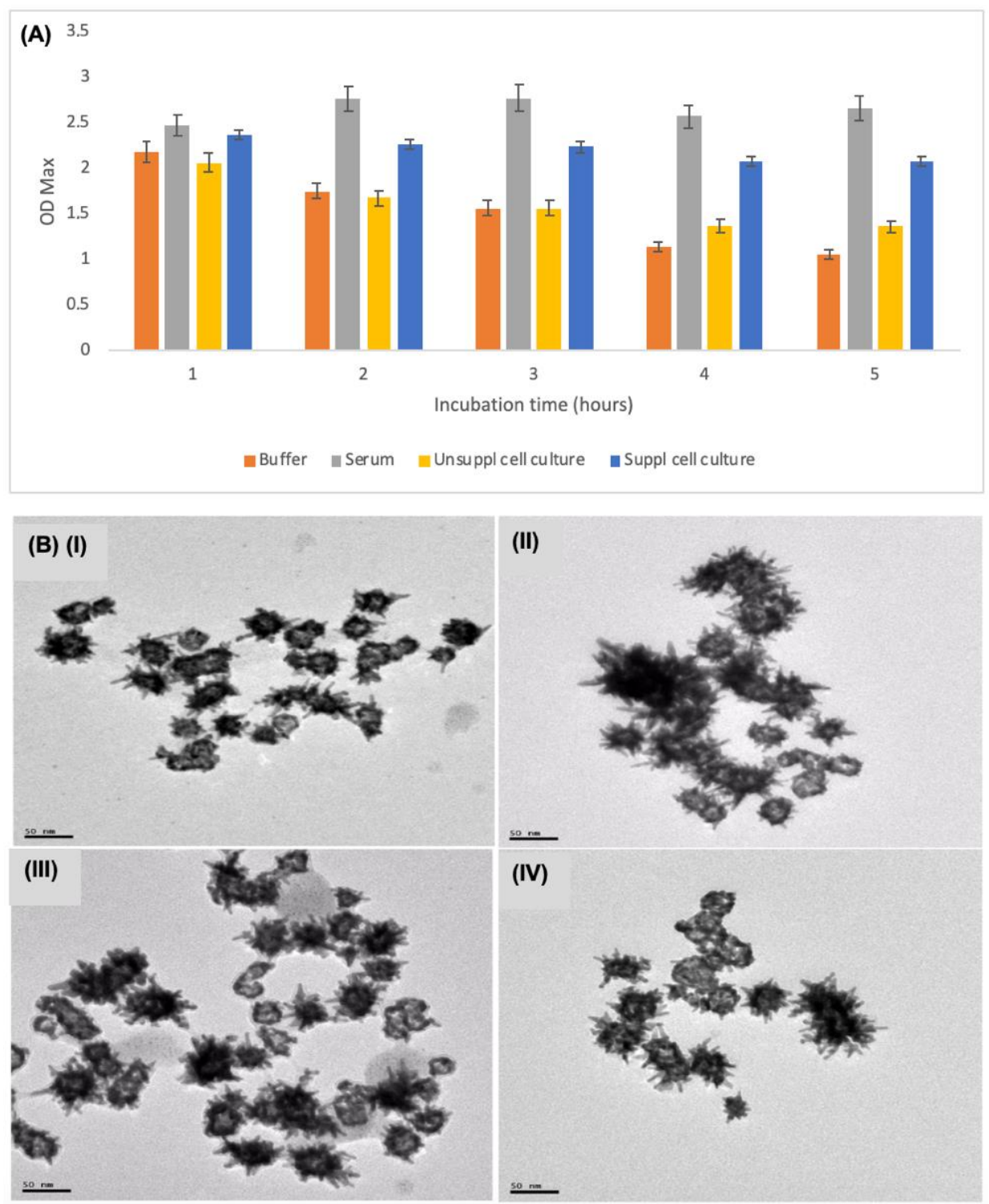

Figure 2. (A) The stability of AuNSs-Cys-GOx bioconjugates in different media based on the UV-vis spectroscopy over a 24-h period. (B) TEM images of the AuNSs-Cys-GOx bioconjugates in different sample matrices: (I) in MES buffer; (II) in serum; (III) in unsupplemented cell media; and (IV) in supplemented cell media.

\subsection{Optimisations of Plasmonic Glucose Detection Conditions in Serum}

The foregoing observations showed that the AuNSs-Cys-GOx bioconjugates displayed both good stability in serum, as well as nanoparticle clustering. Interestingly, the nanostars clustering was recently reported to be an advantage for improving sensitivity in plasmonic assays [62]. The AuNSs-Cys-GOx bioconjugates thus—characterised by enhanced stability and improved sensitivity—were a fit candidate for biosensor fabrication as nanodevices for detection of glucose in serum. Initial attempts at signal generation using serum sample volumes $\geq 20 \mu \mathrm{L}$ proved futile. Despite various attempts of detection condition optimisations, no observable colour change was observed. The failure in signal generation of the nanosensors was attributed to the nanoparticle physiochemical properties changes in complex matrices such as serum $[42,44,45,61]$.

However, when the sample was serially diluted 1000 times, colour changes were observed as shown in Figure 3. The final concentrations of $\mathrm{AgNO}_{3}$ and $\mathrm{NH}_{3}$ in the detection solution were also optimised to a final concentration of $0.25 \mathrm{mM}$ and $20 \mathrm{mM}$, respectively, to generate visible colour 
changes. The biosensor showed ability to differentiate between concentrations of glucose at 1000 times dilution. Sample serial dilution of 1:100-1000 was observed to be optimal for the detection of an analyte in the serum using the fabricated nanodevices. Such a great sample dilution factor offers the advantages of reducing the effects of complex sample interferences [23], and allows the quantification of samples whose concentration is very low, and whose volumes are ultra-low. For simplicity's sake and reducing batch variations in experimentations, a dilution factor of 1:100 was chosen for further experiments that enabled the use of $2 \mu \mathrm{L}$ of serum in a total reaction mixture of $200 \mu \mathrm{L}$.

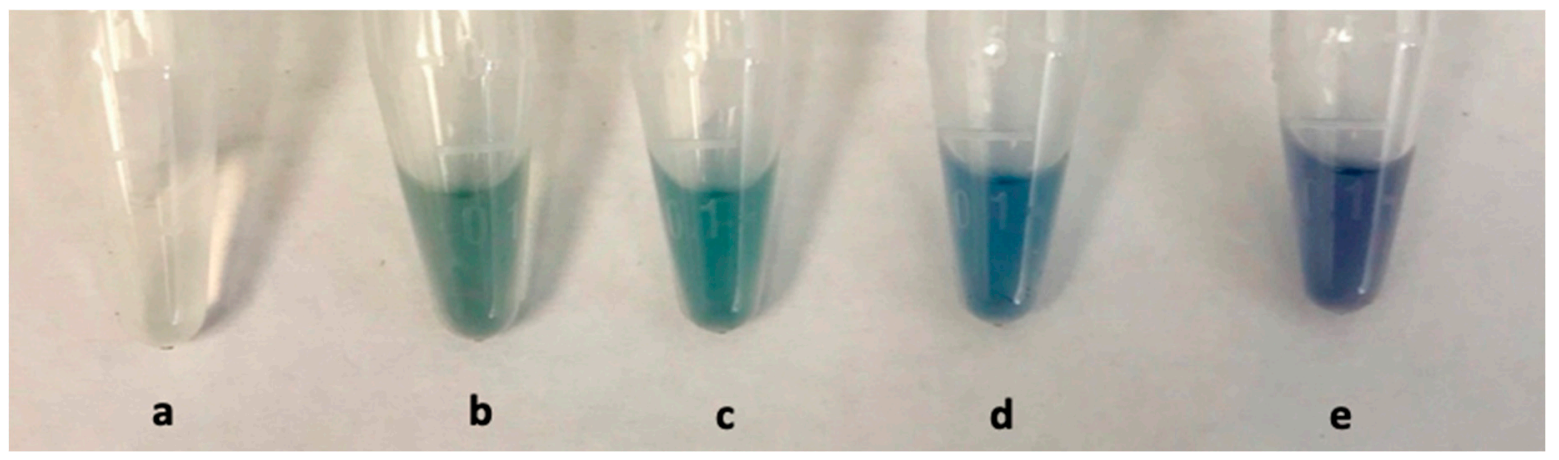

Figure 3. Feasibility of glucose detection in serum using AuNSs as detectors: (a) Blank serum; (b) control sample containing AuNSs in serum; (c) with $0 \mathrm{mmol} / \mathrm{L}$ glucose and detection solution (a mixture of $\mathrm{AgNO}_{3}$ and $\mathrm{NH}_{3}$ ); (d) $0.001 \mathrm{mmol} / \mathrm{L}$ glucose; and (e) $0.002 \mathrm{mmol} / \mathrm{L}$ glucose

\subsection{Plasmonic Glucose Detection by Means of AuNSs Shape-Altering}

Scheme 1 shows the proposed signal-generation mechanism. The silver ions, reduced by $\mathrm{H}_{2} \mathrm{O}_{2}$ produced from oxidised glucose, coated around the plasmonic AuNSs resulting in a shape alteration. The extent of the change in AuNSs morphology depended on the concentration of glucose in the solution. Thus, nanospheres are the potential end-result morphologies of this reaction.

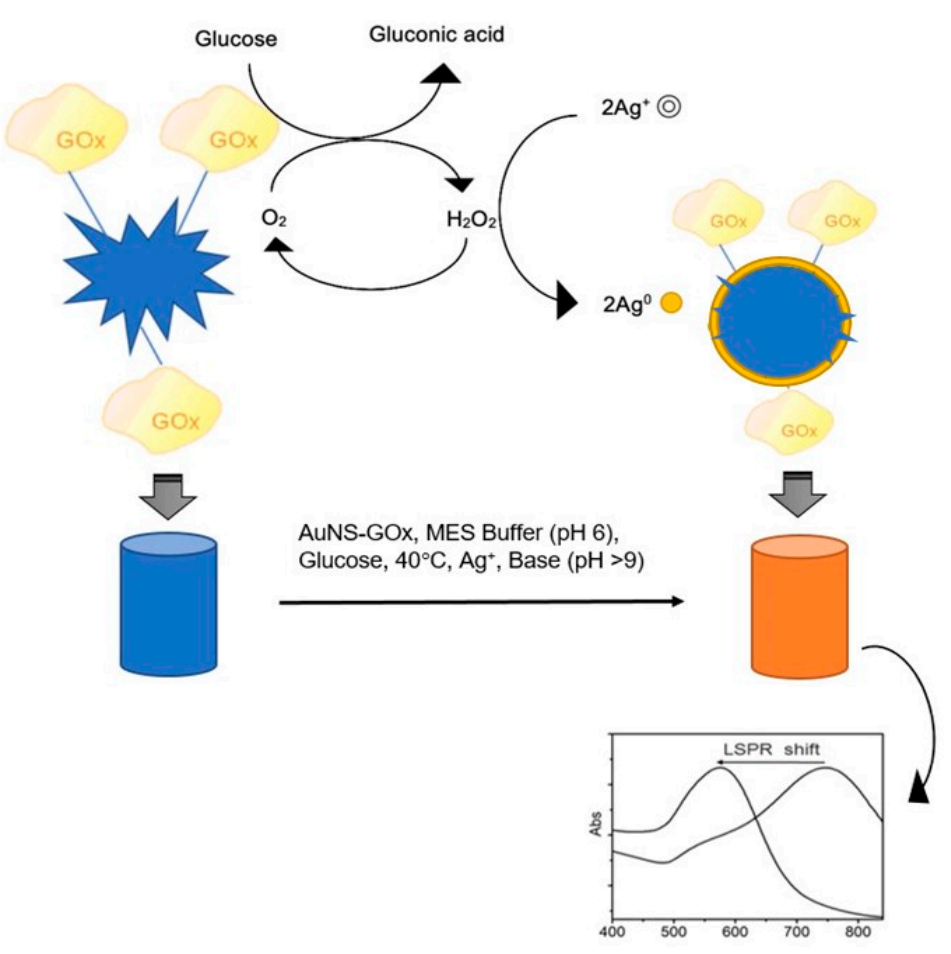

Scheme 1. Proposed signal-generation mechanism by means of biocatalytic shape-altering of gold nanostars (adapted with permission from Phiri et al. [53]). 
The influence of the sample matrix on detection using AuNSs was investigated by detecting different concentrations of glucose measured in the MES buffer and in serum. Figure 4A shows a marked difference in the colour change depending on the sample matrix. More varied colours were observed when the measurement was done in MES buffer compared to serum. The colour changed from blue to purple to orange in MES buffer, while in serum it was from blue to intensified blue to a deep purple colour. Yet, in both matrices there was a visible distinction in colour with increasing concentrations of glucose. This provided an opportunity for this biosensor to be developed and optimised for screening of biological samples with naked eye detection.

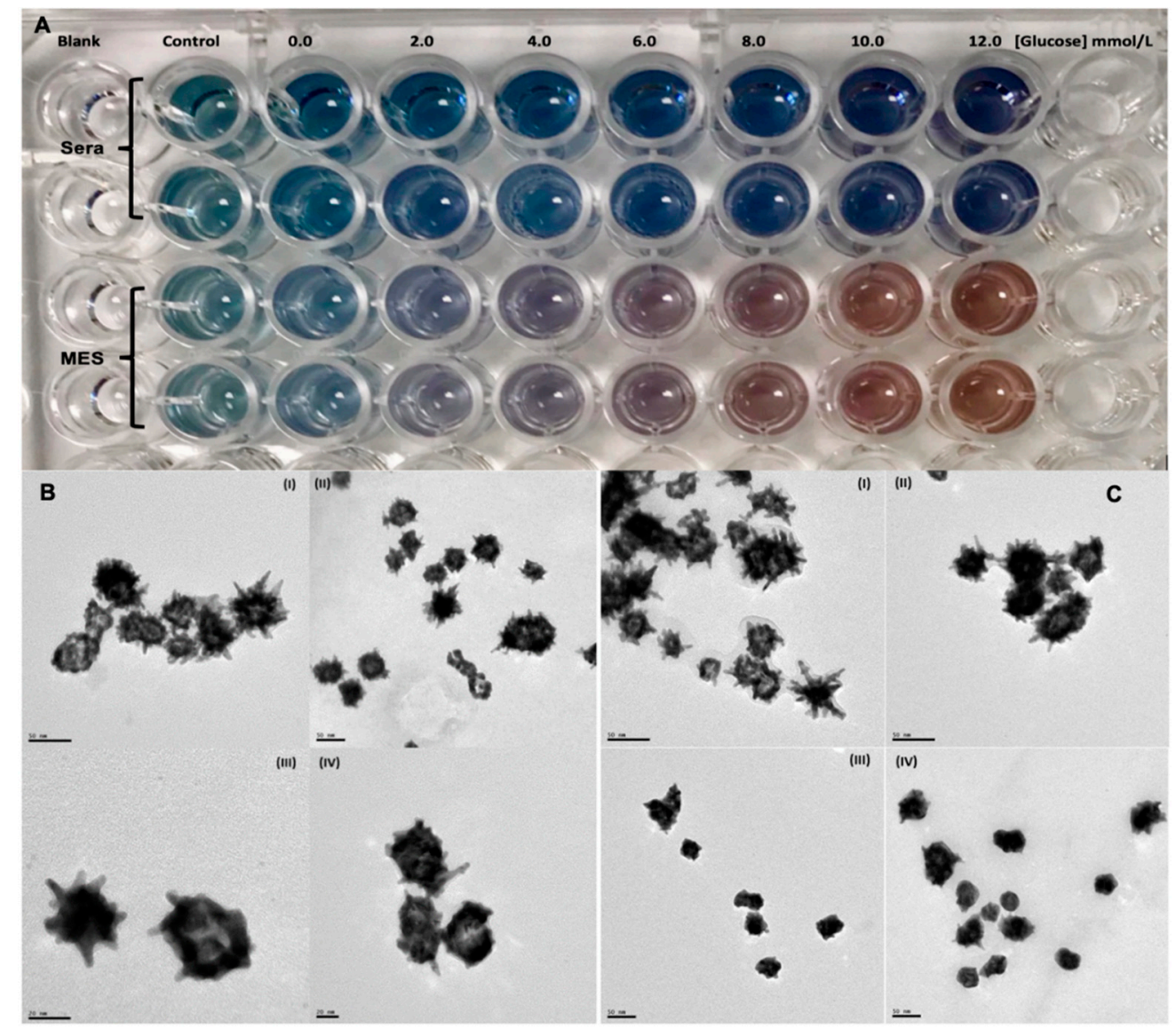

Figure 4. (A) Photograph for colour change of detection solution upon incubation with glucose in the AuNSs-Cys-GOx solution for $45 \mathrm{~min}$; (B) TEM images in serum and (C) in MES buffer, (I) control AuNSs, (II) 0, (III) 6, (IV) $12 \mathrm{mmol} / \mathrm{L}$ glucose.

The morphologies of AuNSs corresponding to selected solutions with different concentrations of glucose are shown in Figure 4B,C. There were clear differences in the change in morphology for AuNSs in serum and MES that explain the degree of the colour changes. In serum, the AuNSs had relatively slight changes in morphology compared to the ones in MES solution. The AuNSs in MES solution became more spherical in morphology due to the silver coating as the glucose concentration increased.

From the analysis of the nanoparticle sizes after being coated with $\mathrm{Ag}^{0}$ as shown in Table 1, no observable growth was found in the size compared to the changes in their morphologies. As opposed to the signal generation mechanism based on the growth of nanoparticles by addition of either $\mathrm{Ag}^{+}$or $\mathrm{HAuCl}^{-}[21,23,26,28]$, this was observed to be merely morphology altering. 
Table 1. Changes in AuNSs diameters corresponding to different glucose concentrations.

\begin{tabular}{ccccc}
\hline Glucose & AuNSs (Control) & $\mathbf{0 ~} \mathbf{~ m m o l} / \mathbf{L}$ & $\mathbf{0 . 0 6} \mathbf{~ m m o l} / \mathbf{L}$ & $\mathbf{0 . 1 2} \mathbf{~ m m o l} / \mathbf{L}$ \\
\hline$\Delta \mathrm{d}(\mathrm{nm})$ in serum & $57.49 \pm 6.24$ & $54.28 \pm 6.79$ & $54.15 \pm 11.42$ & $56.13 \pm 9.08$ \\
\hline$\Delta \mathrm{d}(\mathrm{nm})$ in MES & $50.88 \pm 8.23$ & $50.31 \pm 6.67$ & $48.62 \pm 3.57$ & $50.14 \pm 80.34$ \\
\hline
\end{tabular}

The LSPR peak shifts of AuNSs in serum in Figure 5A showed a total of $80 \mathrm{~nm}$ blueshift. In MES solution however, AuNSs showed a clearer and greater shift of $131 \mathrm{~nm}$ from the control to the highest glucose concentration as shown in Figure 5B. The reason for this observation in the two sample matrices could be due to the interferences caused by proteins and lipoproteins in the serum, which can affect the analytical performance of the biosensor [40]. When the LSPR peak shifts were plotted against the increasing concentration of glucose as shown in Figure 5A,B inserts, the correlation coefficient $\left(R^{2}\right)$ in both serum and MES were 0.99 . This represented a predictable detectable range for glucose concentration with a 100 times dilution of the sample.

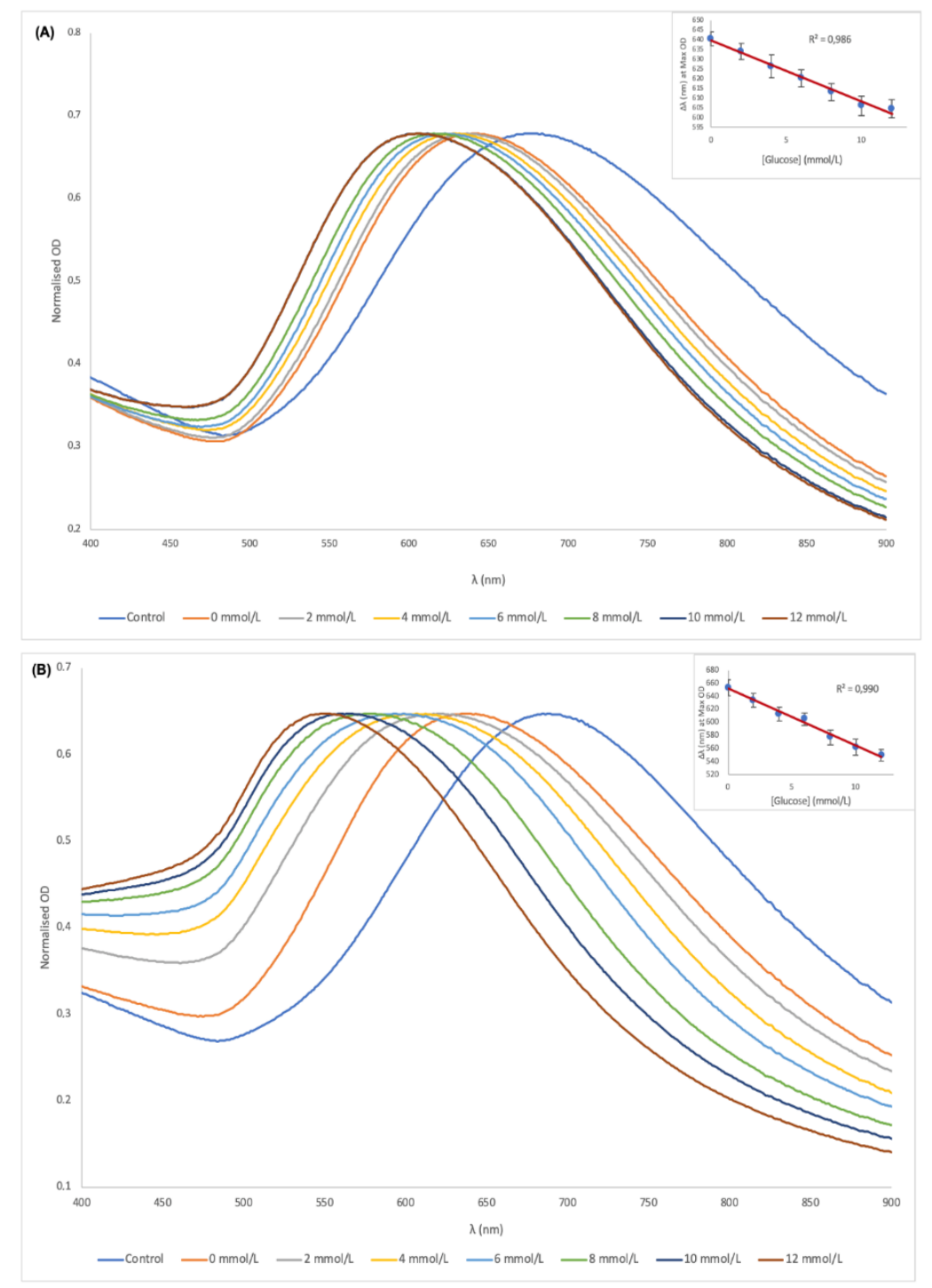

Figure 5. UV-vis spectra of the AuNSs-Cys-GOx bioconjugates and detection solution in the presence of different concentrations of glucose in serum (A) and MES buffer (B); (Inserts) plot of peak shift vs. glucose concentration for serum and MES buffer. 
Figure $6 \mathrm{~A}$ shows the kinetic reaction that was monitored at $550 \mathrm{~nm}$ from the start of incubation with all the optimal reaction conditions with different glucose concentrations. As the reaction proceeded, there was a distinct differentiation between the concentrations of glucose based on the absorbance. The biosensor only required an incubation time of $<15 \mathrm{~min}$ at $37^{\circ} \mathrm{C}$ for sufficient oxidation of glucose and to generate distinguishable colours and plasmonic shifts for detection. Figure $6 \mathrm{~B}$ shows signal generation by addition of detection solution after incubation of the reaction mixture at $37^{\circ} \mathrm{C}$ for $45 \mathrm{~min}$. The biosensor was able to generate distinguishable colorimetric and plasmonic signals between the glucose concentrations in serum in less than $10 \mathrm{~s}$ of detection solution addition. Within 5 min, the signal generation process was near complete. This demonstrates the rapidity of the biosensor both in incubation time and detection process.
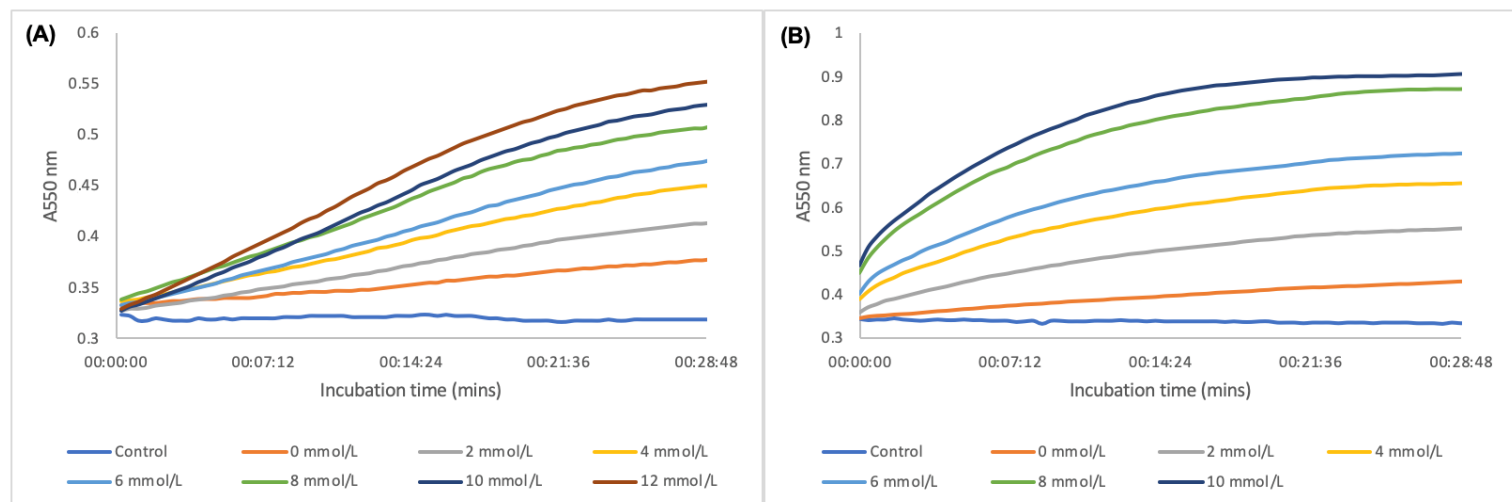

Figure 6. (A) Enzyme kinetic process in oxidising glucose and signal generation by deposition of Ag onto AuNSs during incubation at $37^{\circ} \mathrm{C}$; (B) kinetic colorimetric detection of glucose after incubation at $37^{\circ} \mathrm{C}$ for $45 \mathrm{~min}$ and addition of detection solution.

\subsection{Analytical Performance of the Glucose Biosensor}

The specificity of the glucose biosensor was investigated by using other saccharides as substrates instead of glucose. Figure 7 displays the signal response of the biosensor to these glucose analogues. No significant colour changes or LSPR peak shifts were observed in the presence of other saccharides. The biosensor however, generated a significant response when glucose was the analyte. This observation demonstrated that the signal generation was strongly dependent on the presence of glucose in the reaction solution, and not any other saccharides. The glucose biosensor demonstrated the ability to distinguish the presence and absence of glucose within the limits of detections in the presence of other structural analogues. Furthermore, when L-cysteine and lipids were used as substrates, as shown in Figure 8A,B, minimal LSPR peak shifts were observed for these analytes except for glucose. Figure $8 \mathrm{C}$ shows the colour changes - or lack thereof-of the different analytes. Analytes other than glucose did not produce any change in colour that was significantly different from the blank AuNSs. The biosensor thus demonstrated a specific response for glucose in the presence of potential interferences in serum.

The practical application of the fabricated biosensor was verified by investigating the recovery rates of the biosensor by determining different concentration of glucose as listed in Table 2. The results showed recovery rates of $97 \%$ to $102 \%$ for the three concentrations measured in triplicates. These recovery results were high and could meet the needs of actual clinical sample detection and quantification. 
Table 2. Determination of glucose by the fabricated glucose plasmonic biosensor.

\begin{tabular}{|c|c|c|c|}
\hline Concentration (mmol/L) & $\lambda(\mathrm{nm})$ at OD Max & Concentration Determined (mmol/L) & Recovery (\%) \\
\hline 0.04 & $\begin{array}{l}630 \\
630 \\
633\end{array}$ & $0.039 \pm 0.004$ & 97 \\
\hline 0.08 & $\begin{array}{l}612 \\
616 \\
612\end{array}$ & $0.082 \pm 0.006$ & 102 \\
\hline 0.12 & $\begin{array}{l}598 \\
598 \\
598\end{array}$ & 0.119 & 99 \\
\hline
\end{tabular}

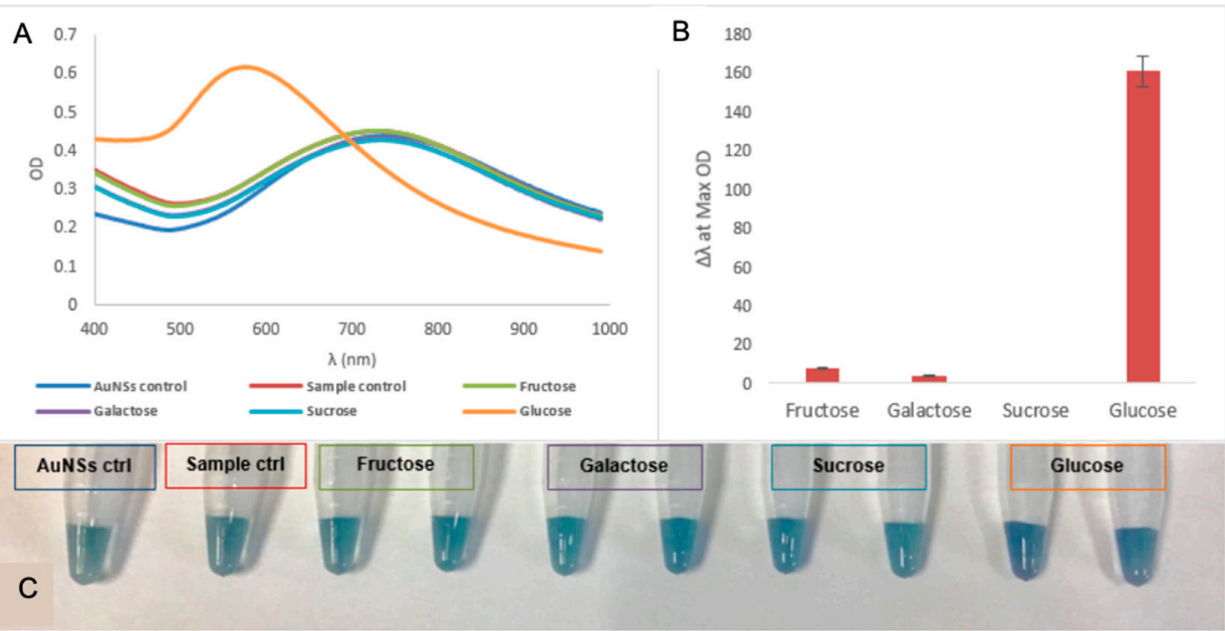

Figure 7. (A) UV-vis spectra of the specificity of the glucose biosensor in the presence of other saccharides at $0.1 \mathrm{mM}$ concentration; (B) corresponding response in terms of $\Delta \lambda$ at OD Max for each saccharide for the glucose biosensor; (C) photograph of the change in colour for the various saccharides.

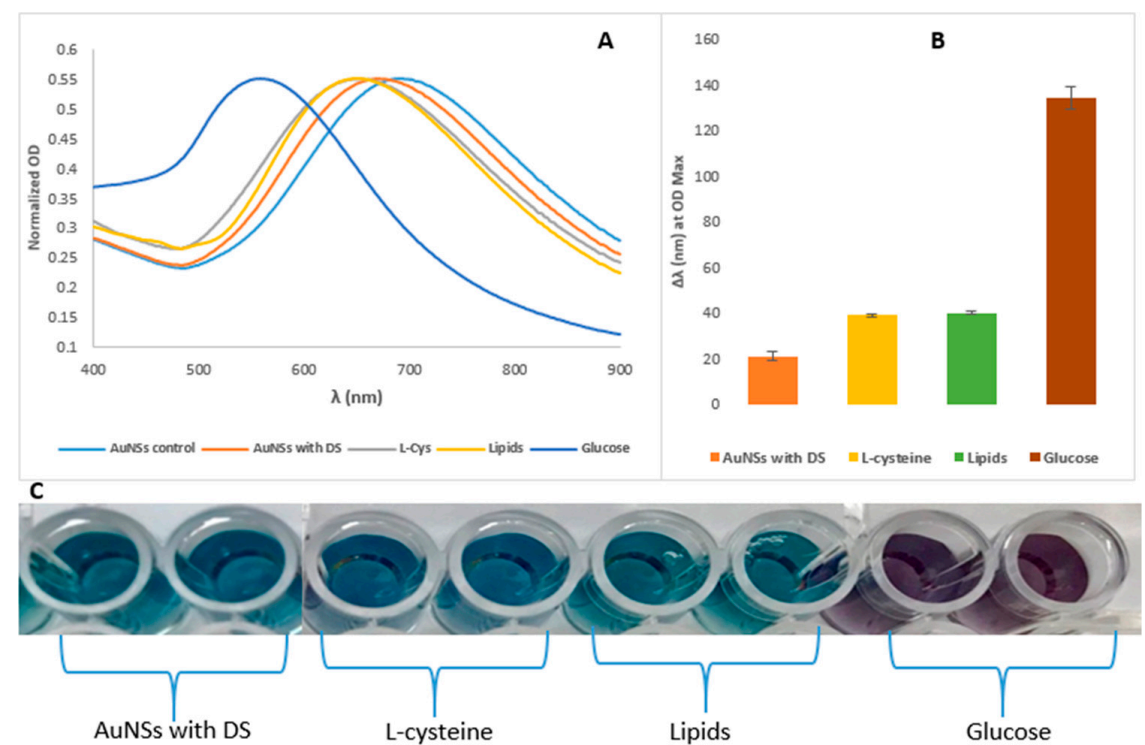

Figure 8. (A) UV-vis spectra of the glucose biosensor's specificity in signal generation in LSPR peak shifts; (B) differences in the magnitude of the LSPR shifts among the compounds, all with the concentration of $0.10 \mathrm{mmol} / \mathrm{L}$. The error bars represent the standard deviation of the mean as the reaction was done in triplicates; and $(\mathbf{C})$ photograph for colour changes or its absence in the presence of other analytes when analysed with the AuNSs-Cys-GOx biosensor. 


\section{Conclusions}

Here presented is a glucose biosensor based on a simple seedless synthesis of gold nanostars, functionalised in a facile way with glucose oxidase for optimal functionality. The assay used AuNSs for greater sensitivity in LSPR peak shifts and colorimetric readouts via biocatalytic altering of their morphologies. Stability in serum and sensitivity in detection was enhanced by nanostar clustering after functionalising with GOx, as well as by the shape-altering mechanism of detection. Furthermore, the sample matrix was observed to influence the colorimetric readout of the assay, with MES buffer solution being more pronounced for the naked eye detection. The biosensor was able to quantify glucose in the serum diluted 1000 times with the ability to distinguish between different concentrations. Such sensitivity can potentially be applied for measuring samples with volumes such as dried blood spots. The assay demonstrated good specificity in glucose detection. Thus, the fabricated glucose biosensor proved to be a rapid kinetic colorimetric assay that utilises a basic entry level laboratory spectrophotometric microplate reader. Such a biosensor could be very useful in resource-constrained regions of the world without state-of-the-art laboratory equipment. This biosensor is a great candidate for potential clinical diagnosis, research and development applications.

Author Contributions: M.M.P. conceived and designed the study, carried out the synthesis, modification, and glucose testing lab work, participated in the data analysis, and drafted the manuscript; B.C.V. and D.W.M. participated in design of the study, data analysis, and drafting and editing of the manuscript. All authors gave final approval for publication.

Funding: This research was partly funded by the Technology Innovation Agency of South Africa. The APC was funded by the North-West University's Centre of Human Metabolomics (CHM).

Acknowledgments: The authors would like to thank Innocent Shuro from the Laboratory for Electron Microscopy, Chemical Resource Beneficiation, North-West University, Potchefstroom, South Africa for assistance with nanoparticle characterization and imaging. The authors would also like to thank Shayne Mason from the Centre of Human Metabolomics, North-West University, Potchefstroom, South Africa, who carried out the ${ }^{1} \mathrm{H}$ NMR analysis.

Conflicts of Interest: The authors declare no conflict of interest.

\section{References}

1. Ferri, S.; Kojima, K.; Sode, K. Review of Glucose Oxidases and Glucose Dehydrogenases: A Bird's Eye View of Glucose Sensing Enzymes. J. Diabet. Sci. Technol. 2011, 5, 1068-1076. [CrossRef] [PubMed]

2. Clark Jr, L.C.; Lyons, C. Electrode systems for continuous monitoring in cardiovascular surgery. Ann. N. Y. Acad. Sci. 1962, 102, 29-45. [CrossRef] [PubMed]

3. Roglic, G. WHO Global report on diabetes: A summary. Int. J. Noncommun. Dis. 2016, 1, 3. [CrossRef]

4. Bihar, E.; Wustoni, S.; Pappa, A.M.; Salama, K.N.; Baran, D.; Inal, S. A fully inkjet-printed disposable glucose sensor on paper. npj Flex. Electron. 2018, 2, 30. [CrossRef]

5. Bandodkar, A.J.; Jia, W.; Yardımc1, C.; Wang, X.; Ramirez, J.; Wang, J. Tattoo-based noninvasive glucose monitoring: a proof-of-concept study. Anal. Chem. 2014, 87, 394-398. [CrossRef]

6. Yi, Y.; Deng, J.; Zhang, Y.; Li, H.; Yao, S. Label-free Si quantum dots as photoluminescence probes for glucose detection. Chem. Commun. 2013, 49, 612-614. [CrossRef] [PubMed]

7. Hu, A.-L.; Liu, Y.-H.; Deng, H.-H.; Hong, G.-L.; Liu, A.-L.; Lin, X.-H.; Xia, X.-H.; Chen, W. Fluorescent hydrogen peroxide sensor based on cupric oxide nanoparticles and its application for glucose and l-lactate detection. Biosens. Bioelectron. 2014, 61, 374-378. [CrossRef]

8. Qi, G.; Wang, Y.; Zhang, B.; Sun, D.; Fu, C.; Xu, W.; Xu, S. Glucose oxidase probe as a surface-enhanced Raman scattering sensor for glucose. Anal. Bioanal. Chem. 2016, 408, 7513-7520. [CrossRef]

9. Hu, Y.; Cheng, H.; Zhao, X.; Wu, J.; Muhammad, F.; Lin, S.; He, J.; Zhou, L.; Zhang, C.; Deng, Y. Surface-enhanced raman scattering active gold nanoparticles with enzyme-mimicking activities for measuring glucose and lactate in living tissues. ACS Nano 2017, 11, 5558-5566. [CrossRef]

10. Radhakumary, C.; Sreenivasan, K. Naked eye detection of glucose in urine using glucose oxidase immobilized gold nanoparticles. Anal. Chem. 2011, 83, 2829-2833. [CrossRef]

11. Xianyu, Y.; Jiang, X. Nanoscale materials and approaches for optical glucose assays. Curr. Opin. Chem. Eng. 2014, 4, 144-151. [CrossRef] 
12. Jiang, Y.; Zhao, H.; Lin, Y.; Zhu, N.; Ma, Y.; Mao, L. Colorimetric detection of glucose in rat brain using gold nanoparticles. Angew. Chem. 2010, 122, 4910-4914. [CrossRef]

13. Wang, F.; Liu, X.; Lu, C.-H.; Willner, I. Cysteine-mediated aggregation of Au nanoparticles: the development of a $\mathrm{H} 2 \mathrm{O} 2$ sensor and oxidase-based biosensors. ACS Nano 2013, 7, 7278-7286. [CrossRef] [PubMed]

14. Jacobs, C.B.; Peairs, M.J.; Venton, B.J. Carbon nanotube based electrochemical sensors for biomolecules. Anal. Chim. Acta 2010, 662, 105-127. [CrossRef] [PubMed]

15. Zhang, W.; Du, Y.; Wang, M.L. Noninvasive glucose monitoring using saliva nano-biosensor. Sens. Bio-Sens. Res. 2015, 4, 23-29. [CrossRef]

16. Gkogkou, D.; Schreiber, B.; Shaykhutdinov, T.; Ly, H.K.; Kuhlmann, U.; Gernert, U.; Facsko, S.; Hildebrandt, P.; Esser, N.; Hinrichs, K. Polarization-and wavelength-dependent surface-enhanced Raman spectroscopy using optically anisotropic rippled substrates for sensing. ACS Sens. 2016, 1, 318-323. [CrossRef]

17. Yonzon, C.R.; Haynes, C.L.; Zhang, X.; Walsh, J.T.; Van Duyne, R.P. A glucose biosensor based on surface-enhanced Raman scattering: improved partition layer, temporal stability, reversibility, and resistance to serum protein interference. Anal. Chem. 2004, 76, 78-85. [CrossRef]

18. Shafer-Peltier, K.E.; Haynes, C.L.; Glucksberg, M.R.; Van Duyne, R.P. Toward a glucose biosensor based on surface-enhanced Raman scattering. J. Am. Chem. Soc. 2003, 125, 588-593. [CrossRef]

19. Guo, Y.; Wu, J.; Li, J.; Ju, H. A plasmonic colorimetric strategy for biosensing through enzyme guided growth of silver nanoparticles on gold nanostars. Biosens. Bioelectron. 2016, 78, 267-273. [CrossRef]

20. Sabu, C.; Henna, T.K.; Raphey, V.R.; Nivitha, K.P.; Pramod, K. Advanced biosensors for glucose and insulin. Biosens. Bioelectron. 2019, in press. [CrossRef]

21. Gao, Y.; Wu, Y.; Di, J. Colorimetric detection of glucose based on gold nanoparticles coupled with silver nanoparticles. Spectrochim. Acta Part A Mol. Biomol. Spectrosc. 2017, 173, 207-212. [CrossRef] [PubMed]

22. Nguyen, N.D.; Van Nguyen, T.; Chu, A.D.; Tran, H.V.; Tran, L.T.; Huynh, C.D. A label-free colorimetric sensor based on silver nanoparticles directed to hydrogen peroxide and glucose. Arab. J. Chem. 2018, 11, 1134-1143. [CrossRef]

23. Rodríguez-Lorenzo, L.; De La Rica, R.; Álvarez-Puebla, R.A.; Liz-Marzán, L.M.; Stevens, M.M. Plasmonic nanosensors with inverse sensitivity by means of enzyme-guided crystal growth. Nat. Mater. 2012, 11, 604-607. [CrossRef] [PubMed]

24. Willner, I.; Baron, R.; Willner, B. Growing metal nanoparticles by enzymes. Adv. Mater. 2006, 18, 1109-1120. [CrossRef]

25. Xiong, Y.; Zhang, Y.; Rong, P.; Yang, J.; Wang, W.; Liu, D. A high-throughput colorimetric assay for glucose detection based on glucose oxidase-catalyzed enlargement of gold nanoparticles. Nanoscale 2015, 7, 15584-15588. [CrossRef] [PubMed]

26. Zayats, M.; Baron, R.; Popov, I.; Willner, I. Biocatalytic growth of Au nanoparticles: from mechanistic aspects to biosensors design. Nano Lett. 2005, 5, 21-25. [CrossRef] [PubMed]

27. Guo, L.; Jackman, J.A.; Yang, H.-H.; Chen, P.; Cho, N.-J.; Kim, D.-H. Strategies for enhancing the sensitivity of plasmonic nanosensors. Nano Today 2015, 10, 213-239. [CrossRef]

28. Yan, Y.M.; Tel-Vered, R.; Yehezkeli, O.; Cheglakov, Z.; Willner, I. Biocatalytic Growth of Au Nanoparticles Immobilized on Glucose Oxidase Enhances the Ferrocene-Mediated Bioelectrocatalytic Oxidation of Glucose. Adv. Mater. 2008, 20, 2365-2370. [CrossRef]

29. Xianyu, Y.; Wang, Z.; Jiang, X. A plasmonic nanosensor for immunoassay via enzyme-triggered click chemistry. ACS Nano 2014, 8, 12741-12747. [CrossRef]

30. Tang, L.; Li, J. Plasmon-based colorimetric nanosensors for ultrasensitive molecular diagnostics. ACS Sens. 2017, 2, 857-875. [CrossRef]

31. Langer, J.; Novikov, S.M.; Liz-Marzán, L.M. Sensing using plasmonic nanostructures and nanoparticles. Nanotechnology 2015, 26, 322001. [CrossRef] [PubMed]

32. Ali, J.; Najeeb, J.; Ali, M.A.; Aslam, M.F.; Raza, A. Biosensors: their fundamentals, designs, types and most recent impactful applications: A review. J. Biosens. Bioelectron. 2017, 8. [CrossRef]

33. Mehrotra, P. Biosensors and their applications-A review. J. Oral Biol. Craniofacial Res. 2016, 6, 153-159. [CrossRef] [PubMed]

34. Cash, K.J.; Clark, H.A. Nanosensors and nanomaterials for monitoring glucose in diabetes. Trends Mol. Med. 2010, 16, 584-593. [CrossRef] [PubMed] 
35. Cheng, H.; Lai, G.; Fu, L.; Zhang, H.; Yu, A. Enzymatically catalytic deposition of gold nanoparticles by glucose oxidase-functionalized gold nanoprobe for ultrasensitive electrochemical immunoassay. Biosens. Bioelectron. 2015, 71, 353-358. [CrossRef]

36. Association, A.D. 2. Classification and diagnosis of diabetes: standards of medical care in diabetes-2018. Diabetes Care 2018, 41 (Suppl. 1), S13-S27. [CrossRef] [PubMed]

37. Zimmet, P.; Alberti, K.G.; Magliano, D.J.; Bennett, P.H. Diabetes mellitus statistics on prevalence and mortality: facts and fallacies. Nat. Rev. Endocrinol. 2016, 12, 616-622. [CrossRef]

38. Ladenson, J.H.; Tsai, L.-M.B.; Michael, J.; Kessler, G.; Joist, J.H. Serum versus heparinized plasma for eighteen common chemistry tests: is serum the appropriate specimen? Am. J. Clin. Pathol. 1974, 62, 545-552. [CrossRef]

39. Nader, R.; Andrea, R.H.; Carl T, W. Tietz Textbook of Clinical Chemistry and Molecular Diagnostics, 6th ed.; Elservier: New York, NY, USA, 2018.

40. Aldewachi, H.; Chalati, T.; Woodroofe, M.; Bricklebank, N.; Sharrack, B.; Gardiner, P. Gold nanoparticle-based colorimetric biosensors. Nanoscale 2018, 10, 18-33. [CrossRef]

41. Urban, D.A.; Rodriguez-Lorenzo, L.; Balog, S.; Kinnear, C.; Rothen-Rutishauser, B.; Petri-Fink, A. Plasmonic nanoparticles and their characterization in physiological fluids. Colloids Surf. B Biointerfaces 2016, 137, $39-49$. [CrossRef]

42. Moore, T.L.; Rodriguez-Lorenzo, L.; Hirsch, V.; Balog, S.; Urban, D.; Jud, C.; Rothen-Rutishauser, B.; Lattuada, M.; Petri-Fink, A. Nanoparticle colloidal stability in cell culture media and impact on cellular interactions. Chem. Soc. Rev. 2015, 44, 6287-6305. [CrossRef]

43. Melby, E.S.; Lohse, S.E.; Park, J.E.; Vartanian, A.M.; Putans, R.A.; Abbott, H.B.; Hamers, R.J.; Murphy, C.J.; Pedersen, J.A. Cascading Effects of Nanoparticle Coatings: Surface Functionalization Dictates the Assemblage of Complexed Proteins and Subsequent Interaction with Model Cell Membranes. ACS Nano 2017, 11, 5489-5499. [CrossRef]

44. Jenkins, S.V.; Qu, H.; Mudalige, T.; Ingle, T.M.; Wang, R.; Wang, F.; Howard, P.C.; Chen, J.; Zhang, Y. Rapid determination of plasmonic nanoparticle agglomeration status in blood. Biomaterials 2015, 51, $226-237$. [CrossRef]

45. Hirsch, V.; Kinnear, C.; Rodriguez-Lorenzo, L.; Monnier, C.A.; Rothen-Rutishauser, B.; Balog, S.; Petri-Fink, A. In vitro dosimetry of agglomerates. Nanoscale 2014, 6, 7325-7331. [CrossRef] [PubMed]

46. Casals, E.; Pfaller, T.; Duschl, A.; Oostingh, G.J.; Puntes, V. Time evolution of the nanoparticle protein corona. ACS Nano 2010, 4, 3623-3632. [CrossRef] [PubMed]

47. Kumar, A.; Bicer, E.M.; Morgan, A.B.; Pfeffer, P.E.; Monopoli, M.; Dawson, K.A.; Eriksson, J.; Edwards, K.; Lynham, S.; Arno, M. Enrichment of immunoregulatory proteins in the biomolecular corona of nanoparticles within human respiratory tract lining fluid. Nanomed. Nanotechnol. Biol. Med. 2016, 12, 1033-1043. [CrossRef] [PubMed]

48. Salvati, A.; Pitek, A.S.; Monopoli, M.P.; Prapainop, K.; Bombelli, F.B.; Hristov, D.R.; Kelly, P.M.; Åberg, C.; Mahon, E.; Dawson, K.A. Transferrin-functionalized nanoparticles lose their targeting capabilities when a biomolecule corona adsorbs on the surface. Nat. Nanotechnol. 2013, 8, 137-143. [CrossRef]

49. Petros, R.A.; DeSimone, J.M. Strategies in the design of nanoparticles for therapeutic applications. Nat. Rev. Drug Discov. 2010, 9, 615-627. [CrossRef]

50. Monopoli, M.P.; Walczyk, D.; Campbell, A.; Elia, G.; Lynch, I.; Baldelli Bombelli, F.; Dawson, K.A. Physicalchemical aspects of protein corona: Relevance to in vitro and in vivo biological impacts of nanoparticles. $J$. Am. Chem. Soc. 2011, 133, 2525-2534. [CrossRef]

51. Verma, A.; Stellacci, F. Effect of surface properties on nanoparticle-cell interactions. Small 2010, 6, 12-21. [CrossRef]

52. Walkey, C.D.; Chan, W.C. Understanding and controlling the interaction of nanomaterials with proteins in a physiological environment. Chem. Soc. Rev. 2012, 41, 2780-2799. [CrossRef] [PubMed]

53. Phiri, M.M.; Mulder, D.W.; Vorster, B.C. Seedless gold nanostars with seed-like advantages for biosensing applications. R. Soc. Open Sci. 2019, 6, 181971. [CrossRef] [PubMed]

54. Phiri, M.M.; Mulder, D.W.; Mason, S.; Vorster, B.C. Facile immobilisation of glucose oxidase onto gold nanostars with enhanced binding affinity and optimal function. R. Soc. Open Sci. 2019, 6. [CrossRef] 
55. Venter, L.; Mienie, L.J.; van Rensburg, P.J.J.; Mason, S.; Vosloo, A.; Lindeque, J.Z. The cross-tissue metabolic response of abalone (Haliotis midae) to functional hypoxia. Biol. Open 2018, 7, bio031070. [CrossRef] [PubMed]

56. Ellinger, J.J.; Chylla, R.A.; Ulrich, E.L.; Markley, J.L. Databases and software for NMR-based metabolomics. Curr. Metab. 2013, 1, 28-40.

57. Li, D.; He, Q.; Cui, Y.; Duan, L.; Li, J. Immobilization of glucose oxidase onto gold nanoparticles with enhanced thermostability. Biochem. Biophys. Res. Commun. 2007, 355, 488-493. [CrossRef] [PubMed]

58. Leff, D.V.; Brandt, L.; Heath, J.R. Synthesis and characterization of hydrophobic, organically-soluble gold nanocrystals functionalized with primary amines. Langmuir 1996, 12, 4723-4730. [CrossRef]

59. Patil, V.; Malvankar, R.; Sastry, M. Role of particle size in individual and competitive diffusion of carboxylic acid derivatized colloidal gold particles in thermally evaporated fatty amine films. Langmuir 1999, 15, 8197-8206. [CrossRef]

60. Aryal, S.; Remant, B.; Dharmaraj, N.; Bhattarai, N.; Kim, C.H.; Kim, H.Y. Spectroscopic identification of SAu interaction in cysteine capped gold nanoparticles. Spectrochim. Acta Part A Mol. Biomol. Spectrosc. 2006, 63, 160-163. [CrossRef]

61. Hirsch, V.; Kinnear, C.; Moniatte, M.; Rothen-Rutishauser, B.; Clift, M.J.; Fink, A. Surface charge of polymer coated SPIONs influences the serum protein adsorption, colloidal stability and subsequent cell interaction in vitro. Nanoscale 2013, 5, 3723-3732. [CrossRef]

62. Park, Y.I.; Im, H.; Weissleder, R.; Lee, H. Nanostar clustering improves the sensitivity of plasmonic assays. Bioconjug. Chem. 2015, 26, 1470-1474. [CrossRef] [PubMed]

(C) 2019 by the authors. Licensee MDPI, Basel, Switzerland. This article is an open access article distributed under the terms and conditions of the Creative Commons Attribution (CC BY) license (http://creativecommons.org/licenses/by/4.0/). 